https://dx.doi.org/10.4314/ijs.v23i1.2

Ife Journal of Science vol. 23, no. 1 (2021)

\title{
BIOLOGICAL SYNTHESIS OF COPPER NANOPARTICLES AND ITS ANTIMICROBIAL POTENTIAL ON SELECTED BACTERIA FOOD-BORNE PATHOGENS
}

\author{
${ }^{1}$ Aderolu, H.A., ${ }^{1}$ Aboaba, O.O,${ }^{2 *}$ Aderolu, A.Z, ${ }^{3}$ Abdulwahab, K.O, ${ }^{4}$ Suliman, A.A and \\ ${ }^{5}$ Emmanuel, U.C. \\ ${ }^{1}$ Department of Microbiology, ${ }^{2}$ Department of Marine Sciences, ${ }^{3}$ Department of Chemistry, University of Lagos, \\ Akoka, Nigeria. ${ }^{4}$ Department of Chemistry, Al-Baha University. Al Makhwah, Saudi-Arabia. ${ }^{5}$ School of Chemistry, \\ University of Manchester, UK \\ *Corresponding author's email: dezaid@yahoo.com or aaderolu@unilag.edu.ng. Tel.: +2348033225139.
}

(Received: $18^{\text {th }}$ July, 2020; Accepted: 28 ${ }^{\text {th }}$ December, 2020)

\section{ABSTRACT}

In this study, copper nanoparticle (CuNPs) was synthesized using green technology and the CuNPs was characterized with Energy Dispersive X-ray (EDX) which confirmed the presence of copper. Scanning Electron Microscopy (SEM) showed the morphology and the average size was calculated to be $2.47 \pm 1 \mathrm{~nm}$. The functional groups were identified by Fourier transform infrared spectroscopy (FTIR) and this revealed that OH functional group was anchored on the surface of the nanoparticles. Antimicrobial activity of the synthesized CuNPs was investigated at varying concentrations $(0.25,0.5,1,2,3,4,5,6$ and $7 \mathrm{mg} / \mathrm{ml})$ dissolved in $100 \%$ dimethyl sulfoxide (DMSO). It was tested against five food borne pathogenic organisms: Salmonella typhimurium, Methicillin resistant Staphylococcus aureus (MRSA), Enterococcus faecalis, Shigella flexneri, and Acinetobacter baumannii using the Kirby Bauer disc diffusion and agar well method. The results showed that the antimicrobial zone of inhibition increased with an increase in concentration of the CuNPs, an average diameter of $25 \mathrm{~mm}$ at $7 \mathrm{mg} / \mathrm{ml}$, $22 \mathrm{~mm}$ at $5 \mathrm{mg} / \mathrm{ml}$ and an average diameter of $13 \mathrm{~mm}$ at $2 \mathrm{mg} / \mathrm{ml}$ of $100 \%$ DMSO. Nanoparticles at 0.25 $\mathrm{mg} / \mathrm{ml}$ and $0.5 \mathrm{mg} / \mathrm{ml}$ concentration failed to produce any clear zone across all the test organisms while only Enterococcus faecalis was sensitive with a clear zone diameter of $10 \mathrm{~mm}$ at $1 \mathrm{mg} / \mathrm{ml} \mathrm{CuNPs}$. MRSA has the least susceptibility: $9 \mathrm{~mm}$ clear zone diameter at $2 \mathrm{mg} / \mathrm{ml}$ and at $7 \mathrm{mg} / \mathrm{ml}$ clear zone diameter of $20 \mathrm{~mm}$, relative to other tested organisms. The test organisms were not sensitive to the following conventional antibiotics: Cefuroxime, Ceftazidime, Erythromycin, Amoxicillin/Clavulanic acid and Cloxacillin, but only sensitive to Gentamicin, Ceftriaxone and Ofloxacin. MRSA on the other hand was not sensitive to all the eight antibiotics tested but susceptible to the CuNPs. The results obtained from this study indicated that copper nanoparticles can be used in the food industry to control both Gram positive and negative bacteria tested.

Keywords: Synthesis, Copper nanoparticles, Antimicrobial activities, Bacteria.

\section{INTRODUCTION}

Food-borne infections caused by bacterial pathogens are a serious public health problem worldwide and accounted for approximately 1.8 million deaths annually (WHO, 2015). Food contamination by pathogenic microorganisms is common and could result in some very severe diseases. According to Food borne Disease Burden Epidemiology Reference Group (FERG), a total of 582 million cases of 22 different food borne enteric diseases with 351,000 deaths were reported globally in 2010 (WHO, 2015). Enteropathogenic Escherichia coli (EPEC) and noro-virus were the main organisms responsible for the fatalities. In the same report, FERG equally revealed that over $40 \%$ of the affected populations were less than 5 years old with the highest disease burden in Africa followed next to South-east Asia region (WHO, 2015).
Food and feed industries alongside pharmaceutical industries are looking for unique and hardy packaging materials and potent preservatives for their products and as a consequence are constantly engaged in developing new methods for combating the menace posed by pathogens. Although antibiotic resistance genes existed long before antibiotics was discovered (D'Costa et al., 2011), the continuous use of antibiotics created favourable conditions for the multiplication of multi-drug resistant microbes with such genes, thus the need to discover alternatives to antibiotics that are safe and could be used in the food and pharmaceutical industries (Bush et al., 2011).

Among the latest methods of tackling bacteria pathogens is the use of nanoparticles which is defined as the understanding and control of 
matter at dimensions between 1 and $100 \mathrm{~nm}$ where unique phenomena enable novel applications (National Nanotechnology Initiative [NNI], 2011). Unique and intrinsic properties of nanoparticles, (small size, shape, composition and long shelf-life stability), could offer numerous distinctive advantages (Schr€ofel et al., 2014; Peralta-Videa et al., 2016; Rafique et al., 2017; Vaseghi et al., 2017) especially as better alternatives in overcoming antibiotics resistance (Weir et al., 2008). Nanoparticles could penetrate the cell wall of most bacteria since the pore sizes are in the nanometer scale (Hajipour et al., 2012). Thus, metallic nanoparticles could be applied in food packaging with satisfactory results in antimicrobial delivery even at low concentrations to eliminate bacteria, fungi, and protozoa pathogens.

Currently, there are several methods for producing nanoparticles which includes chemical, physical and biological (green) methods. The green approach is more effective in satisfying the growing industrial needs since it generates cleaner products under milder, inexpensive and ecofriendly environment and also confers reduction and stabilization of metal ions (Ahmad et al., 2003; Parashar et al., 2009; Roy et al., 20013; Firdhouse and Lalitha, 2013; Shankar and Rhim, 2014; Mohmed, et al., 2017). Other advantages of biosynthesis of nanoparticles is that it could be produced by utilizing plants, enzymes, proteins, microbes, amino acids and starches (Seralathan et al., 2014).

Copper is known as the only solid surface material with biocidal activities on many pathogenic organisms including methicillin-resistant Staphylococcus aureus, vancomycin-resistant Enterococcus, Acinetobacter baumannii, Escherichia coli amongst others. This efficacy is attributed to its broad antimicrobial spectrum and rapid ability to act as electron acceptor or donor (Bruna et al., 2012; Omprakash, 2016). The high surface-tovolume-ratio of copper nanoparticles (CuNPs) are reported to be responsible for its potency against many bacteria and fungi however, the exact mechanism of antimicrobial action is yet to be elucidated. The general view assume a combination of several diverse mechanisms such as blocking biochemical pathway, membrane disruption, complex formation with proteins and DNA damage (Cioffi et al., 2005, Ruparelia et al., 2008 and Ren et al., 2009). CuNPs are known for killing over $99.9 \%$ of pathogens when in contact with them (Bagchi et al., 2012). Interestingly, various studies have indicated that CuNPs are more bioreactive relative to copper oxide nanoparticles because they are more efficient against many resistant bacterial strains (Akhavan and Ghaderi, 2010; Borrelli et al., 2010). In the present study, CuNPs were biologically synthesized using plant extracts and subsequently characterized to determine the antimicrobial potential by varying the concentrations of CuNPs on selected Gram-positive and Gram-negative pathogenic food-borne bacteria.

\section{MATERIALS AND METHODS}

\section{Collection of Plant Samples and Preparation of Extracts}

Fresh African Spinach (Amaranthus bybridus L) and peppermint leaves (Spinacia oleracea L), specimen voucher number 8706 and 8707 respectively, were bought from a local market in Lagos, Nigeria. Proper identification of the leaves was done at the Department of Botany Herbarium of the University of Lagos. The leaves were thoroughly washed with distilled water, air dried for six days and then blended to fine powder. The powder was preserved separately in air-tight containers. Five grams each of spinach and peppermint powder was weighed into a $250 \mathrm{ml}$ conical flask and $50 \mathrm{ml}$ of distilled water was added. The suspension was placed on a hot plate and allowed to boil for 15 min. After boiling, the decoction was allowed to cool and then filtered. The filtrate (extract) was kept in a bottle and subsequently refrigerated until needed.

$\mathrm{CuSO}_{4} \cdot 5 \mathrm{H}_{2} \mathrm{O}$ solution $(0.04 \mathrm{M})$ was prepared and the resulting solution was transferred into a $50 \mathrm{ml}$ standard flask. Five (5) grams of ascorbic acid was dissolved in $50 \mathrm{ml}$ distilled water then stirred until a clear solution was obtained.

\section{Preparation of Test Organisms}

The bacteria used for this study (methicillin resistant Staphylococcus aureus, Enterococcus faecalis ATTC 13311; Salmonella typhimurium, ATTC 12012; Shigella flexnerii and Acinetobacter baumannii) 
were all obtained from Department of Microbiology, University of Ibadan, Nigeria. The organisms were grown on Mueller Hinton (MH) agar (Gram-positive) and MacConkey agar (Gram-negative) overnight at $37^{\circ} \mathrm{C}$. For inoculum preparation, a single colony from the agar plate was transferred to a test tube containing $6 \mathrm{ml}$ of $95 \%$ normal saline solution and vortexed to obtain turbidity equal to a $0.5 \mathrm{Mac}$ farland standard. This was done for each of the test organisms.

\section{Biosynthesis of Copper Nanoparticles}

Green synthesis of nanoparticles using the extracellular approach was carried out following the protocol previously described by Nourbakhsh et al. (2017) and Abdulwahab etal. (2019). Fifty (50) $\mathrm{ml}$ of the copper sulphate solution was measured into a three-necked round bottomed flask. Then $50 \mathrm{ml}$ ascorbic acid was added to the copper sulphate solution followed by $25 \mathrm{ml}$ of the extracts (peppermint and spinach). The flask was attached to a reflux condenser and placed on a magnetic stirrer to homogenize the mixture at $60^{\circ} \mathrm{C}$. Nitrogen gas was incorporated into the set-up to create an inert condition for the reaction and the set-up was left undisturbed for 1 hour. The flask was allowed to cool for 30 minutes and thereafter the mixture was centrifuged and washed with distilled water at 10,000 rpm for 5 minutes. The supernatant was decanted and the resulting brown precipitate (Copper nanoparticles) was collected washed with distilled water and allowed to dry to obtain the fine copper nano-powder.

\section{Characterization of Copper Nanoparticles}

The synthesized nanoparticles were characterized using different tools like the energy dispersive Xray (EDX) analysis to determine the composition of the nanoparticles (Tiwari et al 2016; Agarwal et al 2018), scanning electron microscopy (SEM) for the size and shape of the nanoparticles while, the functional groups on the surface of the particle were identified by Fourier transform infrared spectroscopy (FTIR) (Zhang et al2018). FTIR was carried out using BRUKER spectrophotometer at the Chemistry Department, University of Lagos over the frequency range of approximately 4000$500 \mathrm{~cm}^{-1 .}$ SEM was carried out using a TESCAN Mira 3. EDX was performed with LC FEGSEM + OI EBSD. Both SEM and EDX were done at the
School of Materials, University of Manchester, UK.

In order to test the effectiveness of the nanoproduct against various bacterial pathogens, the CuNPs were prepared in various concentrations $(250 \mu \mathrm{g}-7 \mathrm{mg})$, dissolved in $1 \mathrm{ml}$ of DMSO $(100 \%)$ and then vortexed as follows:
D $0.25=250 \mu \mathrm{g}$ of CuNP in $1 \mathrm{ml}$ of $100 \%$ DMSO,
D $0.5=500 \mu \mathrm{g}$ of CuNP in $1 \mathrm{ml}$ of $100 \%$ DMSO,
$\mathrm{D} 1=1 \mathrm{mg}$ of CuNP in $1 \mathrm{ml}$ of $100 \%$ DMSO,
D2 $=2 \mathrm{mg}$ of CuNP in $1 \mathrm{ml}$ of $100 \%$ DMSO,
$\mathrm{D} 3=3 \mathrm{mg}$ of CuNP in $1 \mathrm{ml}$ of $100 \%$ DMSO,
D4 $=4 \mathrm{mg}$ of CuNP in $1 \mathrm{ml}$ of $100 \%$ DMSO,
$\mathrm{D} 5=5 \mathrm{mg}$ of CuNP in $1 \mathrm{ml}$ of $100 \% \mathrm{DMSO}$,
D6 $=6 \mathrm{mg}$ of CuNP in $1 \mathrm{ml}$ of $100 \%$ DMSO,
$\mathrm{D} 7=7 \mathrm{mg}$ of CuNP in $1 \mathrm{ml}$ of $100 \%$ DMSO

\section{Antimicrobial Susceptibility Test of CuNPs Agar well diffusion method - A sterile cork borer was used to make $6 \mathrm{~mm}$ wells in freshly prepared Mueller Hinton agar already seeded with the $0.1 \mathrm{ml}$ of test organism. Various concentrations of CuNPs solutions from D1-D7 were placed in each well and the plates were incubated for $24 \mathrm{~h}$ at $37{ }^{\circ} \mathrm{C}$. Thereafter, the diameter of clear zone around the wells was measured to the nearest $\mathrm{mm}$.}

\section{Antibiotics susceptibility test}

Kirby Bauer disk diffusion method was used for the antibiotic susceptibility test. Freshly prepared Mueller Hinton agar plates were inoculated with $0.1 \mathrm{ml}$ aliquot of $0.1 \mathrm{ml}$ of each of the test organism. Standardized antibiotic discs (Abtek Biologicals Ltd, Liverpool, England) were placed on the seeded plates. The organisms were tested for their susceptibility to Ceftazidine $30 \mu \mathrm{g}$ (CAZ), Cefuroxime $30 \mu \mathrm{g}$ (CRX), Gentamicin $10 \mu \mathrm{g}$ (GEN), Ceftriaxone $30 \mu \mathrm{g}$ (CTR), Erythromycin 5 $\mu \mathrm{g}$ (ERY), Cloxacillin $5 \mu \mathrm{g}$ (CXC), Ofloxacin $5 \mu \mathrm{g}$ (OFL) and Amoxicillin/Clavulanic acid $30 \mu \mathrm{g}$ (AUG). The plates were incubated for 24 hours at $37^{\circ} \mathrm{C}$. Thereafter, the resistance or susceptibility of each test organism was determined by comparing the zone of clearance obtained for each organism to the Clinical and Laboratory Standards Institute (CLSI) chart for antibiotic susceptibility and resistance. 
The effect of varying concentrations of the CuNPs against the test organisms was carried out using the Kirby Bauer disc diffusion and the agar well diffusion method described above. The CuNPs were weighed- $0.25 \mathrm{mg}, 0.5 \mathrm{mg}, 1 \mathrm{mg}, 2$ $\mathrm{mg}, 3 \mathrm{mg}, 4 \mathrm{mg}, 5 \mathrm{mg}, 6 \mathrm{mg}$ and $7 \mathrm{mg}$ and each dissolved in $1 \mathrm{ml}$ of $100 \%$ DMSO. The nanoparticles dissolved in 100\% DMSO were designated as D0.25 - D7. The different concentrations of the CuNPs were tested on the test organisms in duplicates for the effect of concentration of CuNPs on the antimicrobial potential of the preparations. The inhibition zone for all the concentrations of CuNPs used was measured and recorded.

This procedure was repeated for all the microorganisms and various concentrations of the nanoparticles. The media plates were incubated for 24 hours at $37^{\circ} \mathrm{C}$. The diameters of the zone of inhibition were measured to the nearest millilitre and compared to the Clinical and Laboratory Standards Institute (CLSI) chart for antibiotic susceptibility and resistance.

\section{RESULTS}

\section{Synthesis and Characterization of CuNPs}

In this study, CuNPs were successfully synthesized using leaf extracts as reducing and stabilizing agents, while ascorbic acid was used as the anti-oxidant. A rapid change from blue colour of the copper sulphate solution to a pale green colour upon the addition of the extracts indicated the reduction of the copper solution followed by a brown colour upon the addition of ascorbic acid.

\section{Characterization of Copper Nanoparticles}

The brown coloured compound was characterized as stated in the materials and methods. Biomolecules present in both the synthesized CuNPs and the leaf extracts were analysed using FTIR spectroscopy. Typical spectra obtained are shown in figure 1.

The FTIR of spinach with peppermint extract indicated the presence of $\mathrm{C}-\mathrm{H}$ stretch at peak $3321 \mathrm{~cm}^{-1}$ and $\mathrm{C}=\mathrm{O}$ stretching peak $\left(1637 \mathrm{~cm}^{-1}\right)$ likewise, $\mathrm{C}-\mathrm{H}$ bending group at the peak $820 \mathrm{~cm}^{-1}$, alkyl C=C stretch peak $1608 \mathrm{~cm}^{-1}$, carboxylic $\mathrm{O}-\mathrm{H}$ stretching bond at peak $2360 \mathrm{~cm}^{-1}$ were all detected in the nanoparticle.

The conjugated $\mathrm{C}=\mathrm{C}$ stretching bond and $\mathrm{C}-\mathrm{H}$ bending were both present in the spinach and peppermint extract and also the nanoparticle.

The intensity of the peak $\mathrm{C}=\mathrm{O}$ stretching bond in the copper nanoparticle was reduced compared to the extracts alone suggesting that oxidation must have taken place, hence confirming the use of the extracts as reducing agent.

The peak at $3295 \mathrm{~cm}^{-1}$ attributed to $\mathrm{OH}$ stretching in the extract alone became broadened indicating that there was adsorption of the nanoparticles on the $\mathrm{OH}$ bond. 


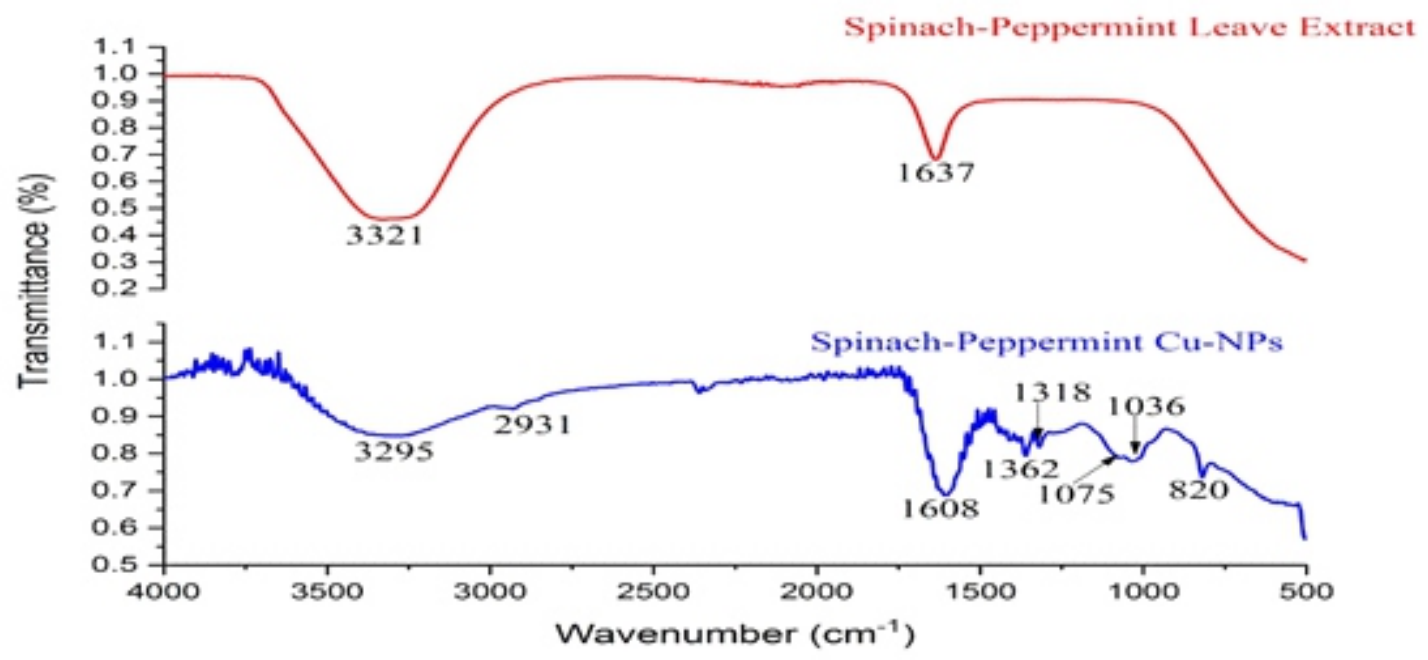

Figure 1: Fourier Transform Infrared Spectroscopy (FTIR) Spectra of Spinach-Peppermint leaves Extracts (Red colour) and of Spinach-Peppermint Capped Cu-NPs (Blue colour)

The EDX result of the nanoparticles capped with the leaves extracts showed copper nanoparticles with no traces of impurities (Figure 2).

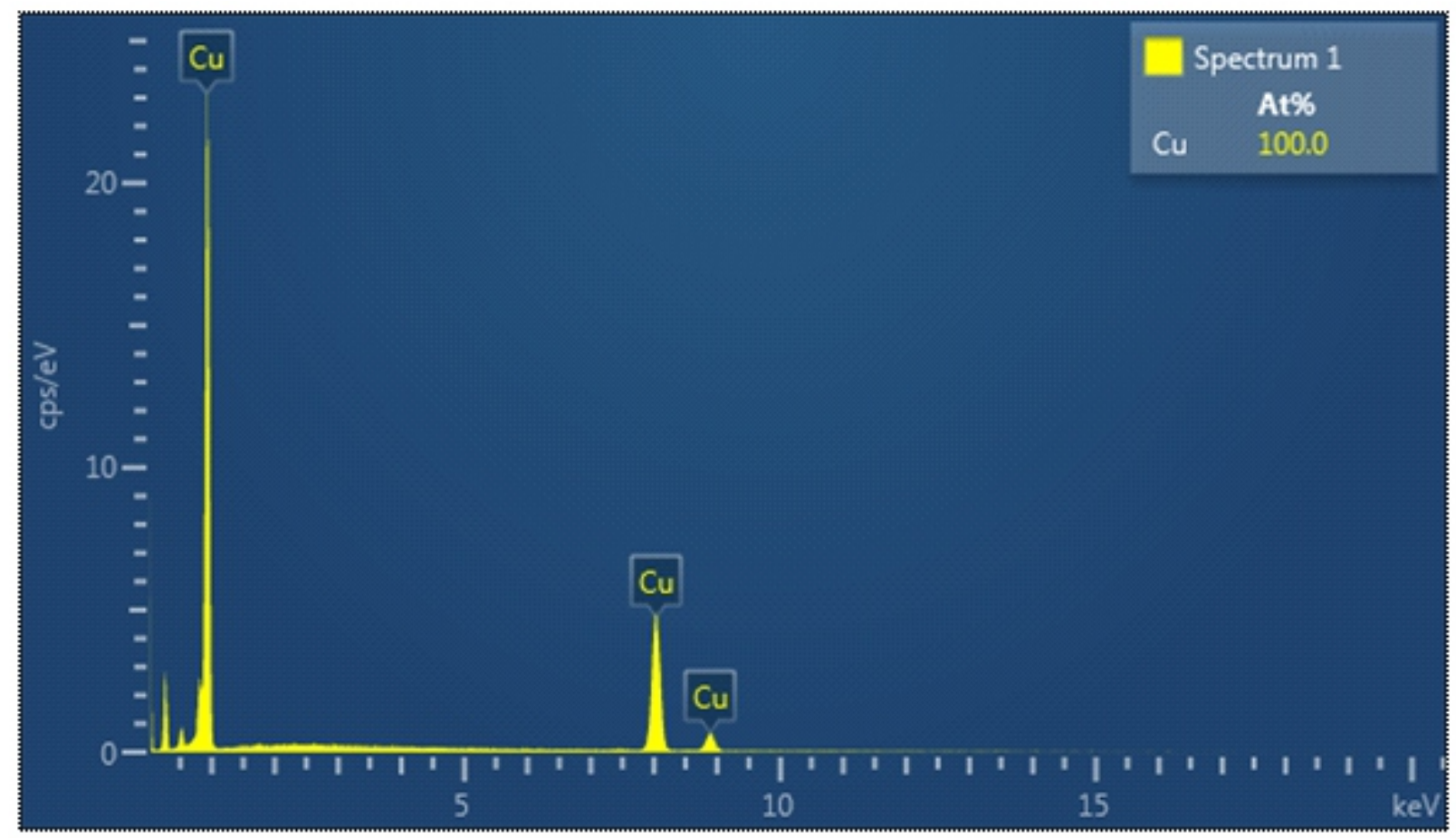

Figure 2: EDX Spectrum of Copper Nanoparticles Capped with Spinach and Peppermint Leaves Extract

The SEM images are shown in figure 3. The copper nanoparticles are spherical shaped with an average size of about $2.47 \pm 1 \mu \mathrm{m}$ 

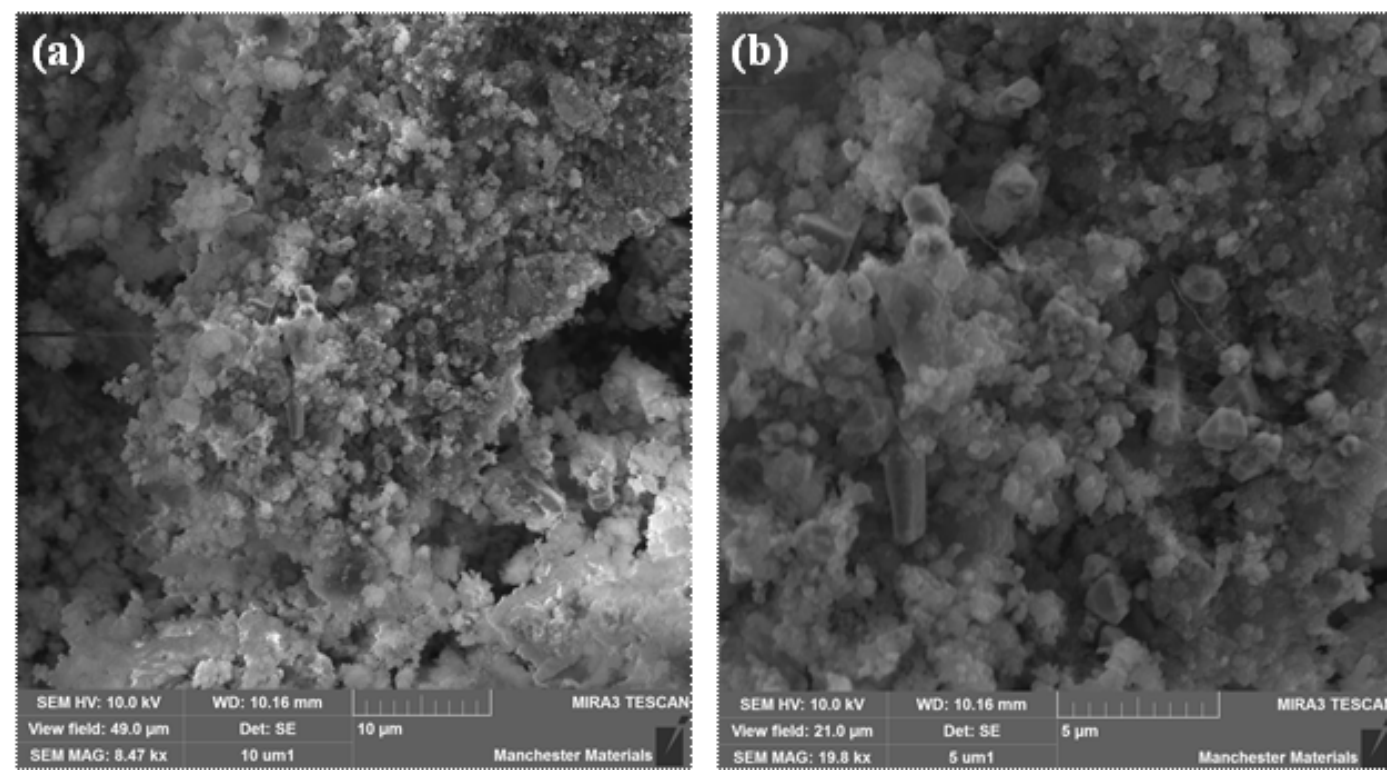

Figure 3: Scanning Electron Micrograph of Copper Nanoparticles at Different Magnifications (a) at 10 $\mu \mathrm{m}$ and (b) $5 \mu \mathrm{m}$

\section{Antimicrobial Potentials of CuNPs}

Antimicrobial susceptibility patterns of CuNPs is summarized in figure 4 . In $100 \%$ of the cases the test organisms showed zone of clearance to CuNPs concentrations of $2 \mathrm{mg} / \mathrm{ml}$ and higher with visible zones of clearance. By implication, $250-500 \mu \mathrm{g} / \mathrm{ml}$ produced no significant zones of clearance. The inhibitory effects follow a pattern of steady increase as the concentration of the CuNPs increased (Figure 4). On the basis of the diameter of zone of clearance, CuNPs is active on S. flexnerii and E. faecalis, and least effective on MRSA strain.

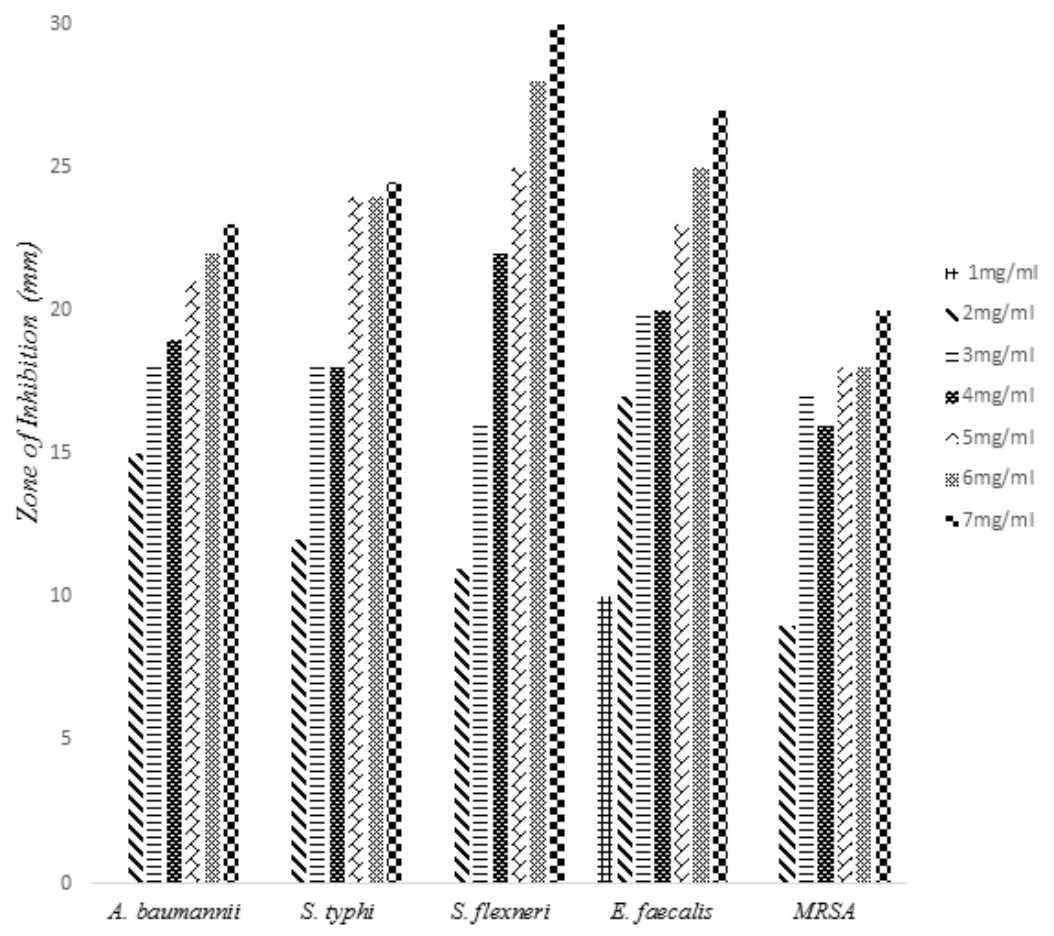

Figure 4: Antibacterial activities of the Biosynthesized Cu-NPs on Agar wells against S.typh i m u ri um, MRSA, E. faecalis, S. flexneri, and A. baumannï (after 24 hours) 
The test organisms were all subjected to susceptibility test using known antibiotics: Ceftazidime, Cefuroxime, Gentamicin, Ceftriaxone, Erythromycin, Cloxacillin, Ofloxacin, and Amoxicillin/Clavulanic acid in their standard concentrations.

All the test organisms exhibited resistance to Ceftazidime and Cefuroxime, Erythromycin and
Amoxicillin/Clavulanic acid. MRSA and E. faecalis were also resistant to Cloxacillin (a narrow spectrum antibiotic for Gram positive bacteria), as shown in figure 5. Gentamicin, Ceftriaxone and Ofloxacin were active against all the test organisms except MRSA. It is noteworthy that MRSA was the only strain that showed striking resistance to all the antibiotics used in this study in contrast to when exposed to CuNPs.

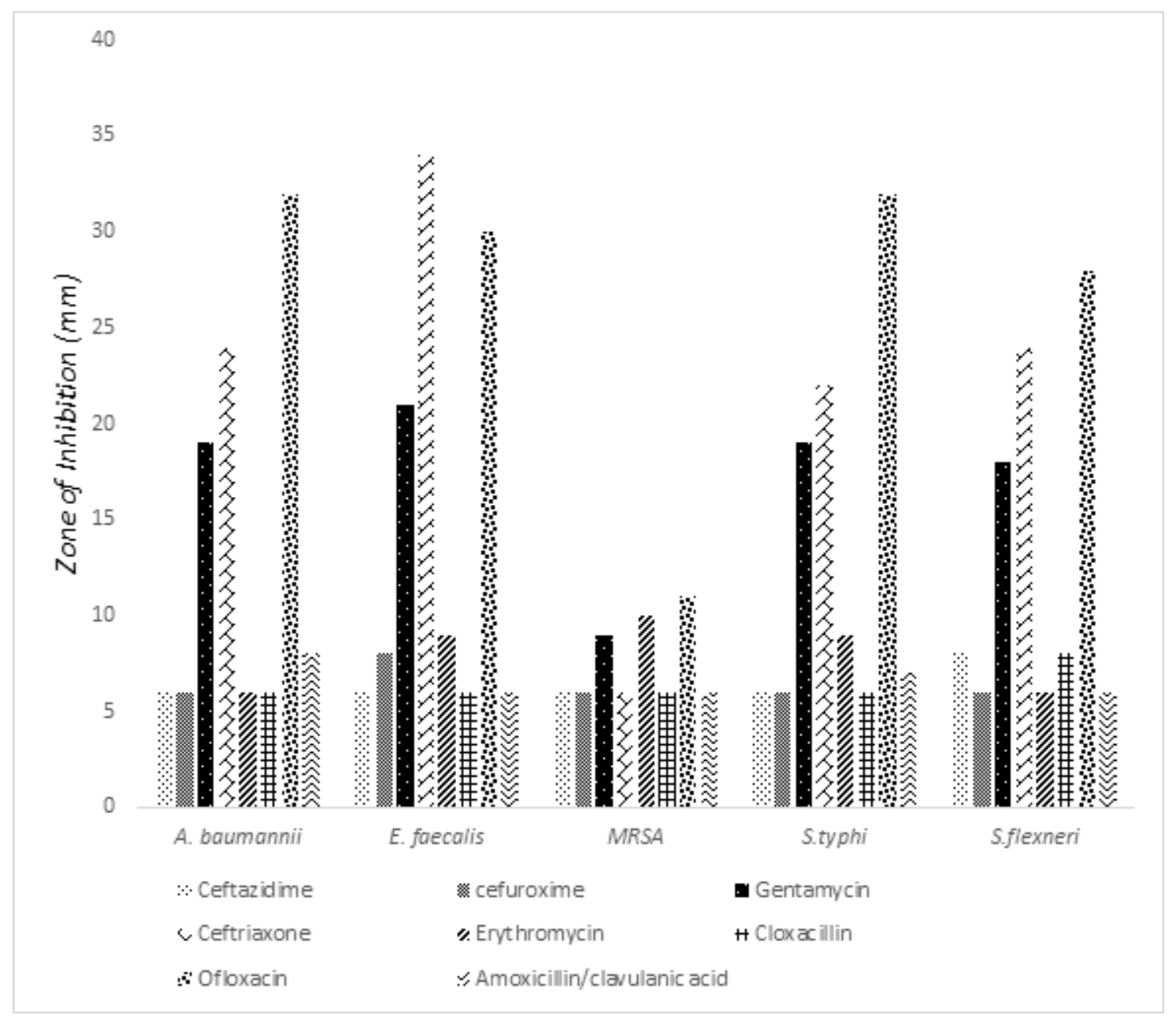

Figure 5: Antibiotics Susceptibility Test for $S$. typhimurium, Methicillin resistant $S$. aureus, E. faecalis, $S$. flexneri, and A. baumannii

\section{DISCUSSION}

Copper has been recognized as a hygienic material since the beginning of civilization, its compounds have been employed as antimicrobial agents and copper ions result in generation of reactive oxygen species that subsequently cause lethal and oxidative damages to cellular structures (Macomber and Imlay, 2009). Copper in its nano form, has significant antibacterial activity as shown by the works of Hassanien et al. (2018) and
Padma et al. (2018) and its synthesis has also been reported as cost effective. The inverse relationship that exists between nanoparticle size and antimicrobial activity has been reported by Azam etal. (2012).

The CuNP was prepared using a convenient and eco-friendly biological synthesis using copper (II) sulphate pentahydrate $\left(\mathrm{CuSO}_{4} .5 \mathrm{H}_{2} \mathrm{O}\right)$ alongside an aqueous extract of Spinacia oleracea (Spinach leaf) 
and Menthapiperita (Mint leaf) with a colour change from light green to reddish brown after the addition of plant extract as capping/reducing agents under nitrogen, convincingly indicate the formation of copper nanoparticles. When $\mathrm{CuSO}_{4}$ dissolves in water, it dissociates into $\mathrm{Cu}^{2+}$ and $\mathrm{SO}_{4}{ }^{2-}$ ions. The $\mathrm{Cu}^{2+}$ ions formed are unstable and are reduced to $\mathrm{Cu}^{\circ}$ through the reducing action of the plant extracts, forming metallic copper nuclei, which can be reduced further in size to form nanoparticles (Padma et al., 2018). The prepared $\mathrm{CuNP}$ was predominantly spherical in nature with an average particle size of $2.47 \mathrm{~nm}$.

The CuNPs exhibited evident antibacterial activity against $S$. typhimurium, Methicillin resistant $S$. aureus, E. faecalis, S. flexneri, and A. baumannii. This could probably be attributed to the spherical and small size of the nanoparticles $(2.47 \mathrm{~nm})$. This is further confirmed by the work of Hassanien et al., (2018) and Azam et al (2012). According to these authors, particle size, particle shape, the concentration of nanoparticles, oxidation state, surface chemistry and the chemical composition of the NPs are some of the factors that could affect the antimicrobial activity of CuNPs.

The antimicrobial efficacy of the synthesized CuNPs was unsurprisingly concentrationdependent. There was a gradual increase in the diameter of zones of clearance as the concentration of CuNPs increased. This trend was also observed by Hassanien et al. (2018) suggesting that higher concentrations of copper nanoparticles are expected to translate to increased antimicrobial activity.

Salmonella typhimurium showed its highest diameter of clearing at $24.5 \mathrm{~mm}$, this is in tandem with the work of Manikandan and Sathiyabama, (2015) where S. typhii showed a diameter of $20 \mathrm{~mm}$ in this study. Highest diameter (zone of clearance) for methicillin resistant $S$. aureus (MRSA) at $20 \mathrm{~mm}$ was recorded at $7 \mathrm{mg} / \mathrm{ml}$ of CuNPs. This is higher than the $6 \mathrm{~mm}$ cleared zone in $S$. aureus reported by Saranyaadevi et al. (2014). E. faecalis, S. flexneri, and $A$. baumannii showed diameters of clearing of $27 \mathrm{~mm}, 30 \mathrm{~mm}$ and $23 \mathrm{~mm}$ respectively.

CuNPs according to literature has been known to be more effective against Gram positive bacteria than Gram negative bacteria by binding to their cell wall (peptidoglycan) (Hassanien et al., 2018; Padma et al., 2018). In this study, the copper nanoparticles exhibited stronger antimicrobial effect on E. faecalis at a low concentration of 1 $\mathrm{mg} / \mathrm{ml}$ where the cells of other test organisms still remain resistant to the effect of the nanoparticles. Methicillin resistant $S$. aureus (MRSA) showed the least cleared zone across the various concentrations of the nanoparticles tested on various Gram positive and negative bacteria studied, though effectiveness of clearance increases with concentrations as found in other bacteria. This could be as a result of the antibiotic defense mechanisms such as drug efflux that these bacteria have and use to evade the activity of many antibiotics.

The test organisms exhibited resistance patterns to some of the antibiotics with only a few antibiotics being effective on the strains. The nanoparticles performed as a broad spectrum antibacterial even against the notorious Methicillin resistant $S$. aureus (MRSA) as compared to some resistance witnessed in the commercial standard antibiotics used in this study. The result obtained with the effectiveness of CuNPs at inhibiting the growth of all the clinical test organisms is not surprising because copper has been reported to present a broader antimicrobial spectrum than other metals due to its ability to quickly donate or receive electrons (Bruna etal., 2012).

Studies have indicated that metallic CuNPs are better bioreactive relative to copper oxide NPs, and are more efficient against many antibiotic resistant bacterial strains (Akhavan and Ghaderi, 2010: Borrelli et al., 2010). The antimicrobial study above indicates that copper nanoparticles can be used as a suitable replacement for antibiotics as it showed no resistance to any of the studied Gram negative and Gram positive bacteria, Also, monodispersed CuNPs have equally been evaluated and tested even against multi-drug resistant strains (Kruk et al., 2015) and according to Hans et al. (2013), it is proven that copper has the ability to kill more than $99.9 \%$ of the disease-causing bacteria within 2 hours of contact time.

\section{CONCLUSION}

In conclusion, analysis of antimicrobial 
effectiveness of green-synthesized CuNPs produced using aqueous extracts of spinach and leaf mint proved to be very effective and successful against notable bacterial pathogens. This study has shown that green synthesis of CuNPs has great advantages like ease of production, economic viability, eco-friendly nature along with it also giving good scope for scaling up and is effective against even multi-drug resistant genera of both Gram positive and Gram negative bacteria. In addition to its incorporation into food preservation following further studies, CuNPs could one day replace antibiotics and harmful chemicals in eliminating food pathogens from food products and industrial processes.

\section{REFERENCES}

Abdulwahab, K.O., Ogunyinka, T., Kolade, S.O. and Adams, L.A. (2019). Green Synthesis of copper nanoparticles, characterization and their catalytic application in the synthesis of dibenzoxazepine. Records of Chemical Sciences, Federal University of Dustin-Ma, Katsina State, 1: 45-49.

Agarwal, H., Venkat Kumar, S., Rajeshkumar, S. Antidiabetic (2018). Effect of silver nanoparticles synthesized using lemongrass (Cymbopogon citratus) through conventional heating and microwave irradiation approach. Journal of Microbiology Biotechnology andFood Sciences; 7:371-376.

Ahmad, A., Mukherjee, P., Senapati, S., Mandal, D., Khan, M.I., Kumar, R., Sastry, M. (2003). Extracellular biosynthesis of silver nanoparticles using the fungus Fusarium oxysporum. Colloids and Surfaces B: Biointerfaces, 28:313-318.

Akhavan, O. and Ghaderi, E. (2010). Cu and CuO nanoparticles immobilized by silica thin films as antibacterial materials and photocatalysts. Surface and Coating Technology, 205: 219-223.

Azam, A., Ahmed, A.S., Oves, M., Khan, M.S., Memic, A., 2012. Size-dependent antimicrobial properties of $\mathrm{CuO}$ nanoparticles against Gram-positive and negative bacterial strains. International Journal of Nanomedicine, 7:3527-3535.

Bagchi, B. Dey, S. Bhandry, S. Das, S. Bhattacharya, A. Basu, R. and Nandy P. (2012). Materials Science and Engineering C, 32:
1897-1905

Borrelli, N., Petzold, O., Schroeder, J.III., Senaratne, W., Verrier, F., and Wei, Y. (2010). US Patent, WO2012135294 A2.

Bruna, J., Peñaloza, A., Guarda, A., Rodríguez, F., and Galotto, M. (2012). Development of $\mathrm{MtCu}_{2}+/ \mathrm{LDPE}$ nanocomposites with antimicrobial activity for potential use in food packaging. Applied Clay Science, 58: 79-87.

Bush, K., Courvalin, P., Dantas, G., Davies, J., Eisenstein, B., Huovinen, P., Jacoby, G., Kishony, R., Kreiswirth, B., and Kutter, E. (2011). Tackling antibiotic resistance. Nature Reviews Microbiology, 9: 894-896.

Cioffi, N. Torsi, L. Ditaranto, N. Tantillo, G. Ghibelli, L. Sabbatini, L Bleve-Zacheo, T. D'Alessio, M. Zambonin, P.G Traversa, E (2005). Chemistry of Materials, 17: $5255-5262$.

D'Costa, V., King, C., Kalan, L., Morar, M., Sung, W., Schwarz, C., Froese, D., Zazula, G., Calmels, F., Debruyne, R., Golding, G., Poinar, H., and Wright, G. (2011). Antibiotic resistance is ancient. Nature, 477: 457-461.

Firdhouse, M.J., Lalitha, P. (2013) Green synthesis of silver nanoparticles using the aqueous extract of Portulaca oleracea. Asian Journal of Pharmaceutical and Clinical Research, 6:92-94.

Hajipour, M., Fromm, K., Ashkarran, A., de Aberasturi, D., de Larramendi, I., Rojo, T., Serpooshan, V., Parak, W., and Mahmoudi, M. (2012). Antibacterial properties of nanoparticles. Trends in Biotechnology, 30: 500-511.

Hans, M. Erbe A, Mathews, S., Chen, Y., Solioz, M., Mücklich, F. (2013). Role of copper oxides in contact killing of bacteria. Langmuir, 29:16160-16166.

Hassanien, R., Husein, D. and Al-Hakkani, M. (2018). Biosynthesis of copper nanoparticles using aqueous Tilia extract: antimicrobial and anticancer activities. Heliyon, 4 (12): e01077.

Kruk, T., Szczepanowicz, K., Stefanska, J., Socha, R., and Warszynski, P. (2015). Synthesis and antimicrobial activity of monodisperse copper nanoparticles. Colloids and Surfaces B: Biointerfaces, 128: 17-22.

Macomber, L., Imlay, J.A., 2009. The iron-sulfur 
clusters of dehydratases are primary intracellular targets of copper toxicity. Proceedings of the National Academy of Sciences, 106 (20), 8344-8349.

Manikandan, A. and Sathiyabama, M. (2015). Green Synthesis of Copper-Chitosan Nanoparticles and Study of its Antibacterial Activity. Journal of Nanomedicine and Nanotechnology, 6: 1:1-6

Mohmed, A. A., Fouda, A., Mamdoh, S.E., Hassan, S.E., Shaheen, T. I., and Salem, S. S. (2017). Enhancing of cotton fabric antibacterial properties by silver nanoparticles synthesized by new Egyptian strain Fusarium keratoplasticum A1-3. Egyptian Journal of Chemistry, 60: 63e71.

Nourbakhsh, S. Habibi, S, Rahimzadeh, M. (2017). Copper nano-particles for antibacterial properties of wrinkle resistant cotton fabric. Materials Today Proceedings, 4:7032-7037.

National committee for Clinical Laboratory Standards (NCCLS) (2012). Performance standards for antimicrobial disks susceptibility tests. Twenty second $\left(22^{\text {nd }}\right)$ informational supplement NCCLS document M100-S22, Volume 32, Number 3, Wayne (PA): Clinical Laboratory Standards Institutes (CLSI).

National Nanotechnology Initiative (NNI) (2011). National Science and Technology Council. Committee on Technology, Subcommittee on Nanoscale Science, National Technology Initiative Strategic, Available at: www.nano.gov.

Omprakash, K. (2016). Controlling-infectionsdue-to-hvac-system. Cooling India. Chary Publications.

Padma, P., Banu, S. and Kumari, s. (2018). Studies on green synthesis of copper nanoparticles using Punica granatum. Annual Research \& Review in Biology, 23(1): 1-10.

Parashar, V., Parashar, R., Sharma, B., Pandey, A.C. (2009). Parthenium leaf extract mediated synthesis of silver nanoparticles: a novel approach towards. Digest Journal of Nanomaterials and Biostructures, 4:45-50.

Peralta-Videa, J., Huang, Y., Parsons, J., Zhao, L., Lopez-Moreno, L., Hernandez-Viezcas, J., and Gardea-Torresdey, J. (2016). Plantbased green synthesis of metallic nanoparticles: scientific curiosity or a realistic alternative to chemical synthesis? Nanotechnology for Environmental Engineering, 1: 4.

Rafique, M., Shaikh, A., Rasheed, R., Tahir, M., Bakhat, H., Rafique, M., and Rabbani, F. (2017). A review on synthesis, characterization and applications of copper nanoparticles using green method, Nanotechnology, 12 (4): 1750043.

Ren, G. Hu, D. Cheng, E.W.C. Vargas-Reus, M.A. Reip, P. Allaker, R.P (2009). Characterization of copper oxide nanoparticles for antimicrobial application. International Journal of Antimicrobial. Agents, 33: 587-590.

Roy, N., Gaur, A., Jain, A., Bhattacharya, S., Rani, V. (2013). Green synthesis of silver nanoparticles: an approach to overcome toxicity. Environmental Toxicology and Pharmacology, 36:807-812.

Ruparelia, J.P., Chatterjee, A.K., Duttagupta, S.P., Mukherji, S., (2008). Strain specificity in antimicrobial activity of silver and copper nanoparticles. Acta Biomaterialia, 4 (3): 707-716.

Saranyaadevi, K., Subha, V., Ernest-Ravindran, R. and Renganathan, S. (2014). Synthesis and characterization of copper nanoparticle using Capparis zeylanica leaf Extract. International Journal of Chemtech Research, $\mathbf{6}$ : 4533-4541

Schr€ofel, A., Kratosova, G., Safarík, I., Safaríkova, M., Raska, I., and Shor, L. (2014). Applications of biosynthesized metallic nanoparticles a review. Acta Biomaterialia, 10: 4023-4042.

Seralathan J, Stevenson P, Subramaniam S, Raghavan R, Pemaiah B, Sivasubramanian A, Veerappan A (2014). Spectroscopy investigation on chemo-catalytic, free radical scavenging and bactericidal properties of biogenic silver nanoparticles synthesized using Salicornia brachiata aqueous extract. Spectrochimica Acta $A$ Molecular Biomolecular Spectroscopy, 118:349-355.

Shankar, S., Rhim, J.W. (2014). Effect of copper salts and reducing agents on characteristics and antimicrobial activity of copper nanoparticles, Materials Letters, 
132:307-311.

Tiwari, M., Jain, P., Chandrashekhar Hariharapura, R., Narayanan, K., Bhat, K.U., Udupa, N., Rao, J.V. (2016). Biosynthesis of copper nanoparticles using copper-resistant Bacillus cereus, a soil isolate. Process Biochemistry, 51:1348-1356.

Vaseghi, Z., Nematollahzadeh, A., and Tavakoli, O. (2017). Green methods for the synthesis of metal nanoparticles using biogenic reducing agents. Reviews in Chemical Engineering, 34 (4): 529-559

Weir, E., Lawlor, A., Whelan, A., and Regan, F.
(2008). The use of nanoparticles in antimicrobial materials and their characterization. Analyst, 133: 835-845.

WHO (2015). World Health Organization. From farm to plate, make food safe. Available from: http://www.who.int/mediacentre/ news/releases

Zhang, L. Q. B., Xing, X., Zhao, Y., Cai, R., Wang, W., Gu, Q. (2018). Biosynthesis of copper nanoparticles using Shewanella loibica PV-4 with antibacterial activity: novel approach and mechanisms investigation. Journal of Hazardous Materials, 347:141-149. 